\title{
SYNTHESIS AND TENSILE PROPERTY OF NANOCRYSTALLINE METAL COPPER
}

\author{
X.J. Wu ${ }^{1,2}$, L.G. Du ${ }^{1}$, H.F. Zhang ${ }^{1}$, J.F. Liu' ${ }^{1}$, Y.S. Zhou ${ }^{1}$, Z.Q. Li ${ }^{1}$, L.Y. Xiong ${ }^{3}$ and Y.L. Bai ${ }^{2}$ \\ 1, Department of Materials Scicnce and Enginneering, Zhejiang University, \\ Hangzhou 310027, China \\ 2, Laboratory of Non-linear Mechanics of Continuous Media, Institute of Mechanics, \\ Academia Sinica, Beijing 100080, China \\ 3, Institute of Metals Research, Academia Sinica, Shenyang 110015, China
}

\begin{abstract}
A large disk-shaped specimen of nanocrystalline metal copper, with a diameter of $80 \mathrm{~mm}$ and thickness $5 \mathrm{~mm}$, was synthesized by an inert gas condensation and insitu warm compacting technique. The grain size and density of the specimen are $36 \mathrm{~nm}$ and $94.3 \%$ of standard density, respectively. The positron lifetime and intensity were measured for monitoring the defects in the specimen. The results indicated that the size and amount of the vacancies and microvoids in the large specimen are close to that found in the small specimens of other nanostructured materials prepared by the same technique. The tensile stress-strain curve has been precisely measured by using the load cell and foil strain gauge. The results showed that the elastic modulus, yield stress, fracture strength, elongation and mirohardness are $0.65,1.42,1.82,0.20$ and 6 times of that for coarse-grained polycrystalline metal copper, respectively. O1999 Acta Metallurgica Inc.
\end{abstract}

\section{INTRODUCTION}

Many studies revealed that the microhardness of nanostructured (nano)-metals, -alloys, -intermetallic compounds and -ceramics enhances by factors from 2 to 7 than their coarsegrained counterparts (1-4). This novel mechanical property is important both for fundamental research and applications of nano-materials. But the hardness is insufficient for evaluating the mechanical property of materials. Elastic modulus, strength and ductility, which can be conducted from tensile tests, are generally used to characterize the basic mechanical property. Up to now, only a few results concerning tensile tests for nano-materials have been reported (5-9), owing to the difficulty for fabricating relatively large specimens with grain size less than $100 \mathrm{~nm}$. On the other hand, mechanical properties are sensitive to imperfection and purity of materials, hence synthesis of fully dense nano-materials without contamination is very important.

The present paper describes the fabrication of a large specimen of nano-metal $\mathrm{Cu}$ by means of an inert gas condensation and in situ warm compacting technique, provides the experimental results on defects and tensile properties of the specimen, and indicates the influence of air contamination of nanoparticles in the specimen on the tensile property. 


\section{EXPERIMENTAL PROCEDURE}

The nano- $\mathrm{Cu}$ specimen used in this investigation was synthesized by an inert gas condensation and in-situ warm compacting technique. The nano-particles of metal copper were fabricated from high purity precursor metal copper evaporated by ARC heating into 400 $\mathrm{Pa}$ of $\mathrm{Ar}$ gas in an evaporating chamber. After an evaporation /gas condensation run, the vacuum of evaporating chamber was returned to a vacuum of $9 \times 10^{-6} \mathrm{~Pa}$. Subsequently the collected nano-particles were consolidated at $200^{\circ} \mathrm{C}$ in an in-situ compacting unit under a pressure of $1.0 \mathrm{GPa}$. The dimension of a disc-shaped specimen produced is $80 \mathrm{~mm}$ in diameter and $5 \mathrm{~mm}$ thickness, as shown in Figure 1, which might be the largest specimen of nanometals synthesized by inert gas condensation and in-situ compacting technique. The density of the specimen was measured by using Archimedes principle. The average grain size was determined by a Fourier analysis x-ray diffraction (XRD). The positron life times and intensities, which are sensitive to defects in nano-materials, were monitored by using a fastfast coincidence ORTEC system.

The tensile tests were performed on a tensile device attached in a S-570 type scanning electron microscope (SEM) for the samples with the gauge length of $6 \mathrm{~mm}$, width $2 \mathrm{~mm}$ and thickness $1.5 \mathrm{~mm}$, which were cut from the large disc of nano-Cu. The stress and strain of every sample were precisely measured by means of a load cell and a constantan foil strain gauge attached on the center of the gauge section. For investigating the influence of contamination on tensile property, another disc of nano- $\mathrm{Cu}$ was prepared by exposing the nano-particles in air for 1 hour before compacting in vacuum.

\section{RESULTS AND DISCUSSION}

The average grain size and density of the specimen prepared are $36 \mathrm{~nm}$ and $94.3 \%$ of standard density, respectively. The results of positron life times and intensities for nano- $\mathrm{Cu}$ were listed in Table 1. The relevant results found in nano-Fe (10,11), $-\mathrm{NiP}(12)-\mathrm{TiO}_{2}(13)$ were also listed in Table 1 for comparison. The positron life times $\tau_{1}$ and $\tau_{2}$ for nano-Cu are in the range of that measured in nano-Fe, $-\mathrm{TiO}_{2}$ and $-\mathrm{NiP}$. The lifetime $\tau_{1}(175 \pm 5 \mathrm{ps})$ for nano- $\mathrm{Cu}$ is nearly the same as that for nano- $\mathrm{Fe}(180 \pm 15 \mathrm{ps})$ and hence should be taken as the indication of the presence of free volumes with the size comparable to that of a monovacancy in the interfaces. The lifetime $\tau_{2}(345 \pm 7 \mathrm{ps})$ for nano-Cu is quite similar to that for nano-Fe ( $360 \pm 30 \mathrm{ps}),-\mathrm{NiP}(350 \pm 20 \mathrm{ps})$ and $-\mathrm{TiO}_{2}(385 \pm 16 \mathrm{ps})$ and should be corresponding to the presence of free volumes, with the size comparable to a cluster of 10-15 vacancics, at the intersection of two or three crystallite interfaces. The lifetimes $\tau_{3}(3498 \pm 763 \mathrm{ps})$ for nano- $\mathrm{Cu}$ is longer than that found in nano-Fe, $-\mathrm{NiP}$ and $-\mathrm{TiO}_{2}$. It should bc attributed to the formation of larger microvoids in nano- $\mathrm{Cu}$. The size of microvoids in the present specimen is larger than that found in nano- $\mathrm{Fe},-\mathrm{NiP}$ and $-\mathrm{TiO}_{2}$, but the amount of them is quite small (only $0.6 \pm 0.3 \%$ ) and less than that found in nano-Fe and $-\mathrm{TiO}_{2}$. The main defects in the present specimen are monovacancies and vacancy-clusters with the equivalent amount $\left(I_{1} / I_{2}=1.08\right)$. In general, the vacancy and microvoid-like defects formed in the present large specimen are similar to that found in the small specimens of nano- $\mathrm{Fe}$ and $-\mathrm{TiO}_{2}$, synthesized by the same technique. 


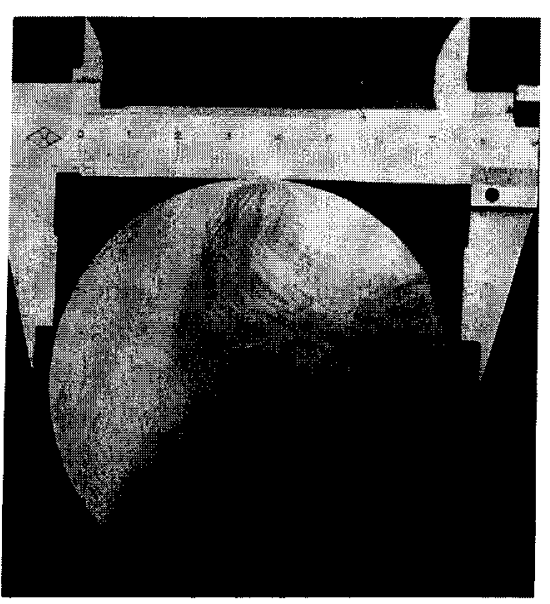

Figure 1, Photograph of a large specimen of nanocrystalline metal copper with diameter of $80 \mathrm{~mm}$ and thickness $5 \mathrm{~mm}$.

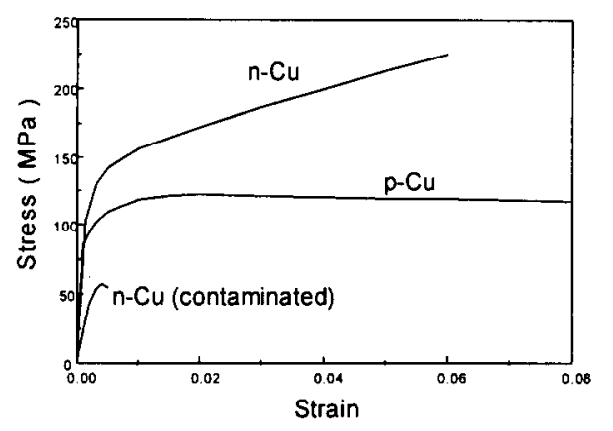

Figure 2, Stress-strain curves for nanocrystalline metal copper with clean and air contaminated interfaces, as well as for coarse-grained polycrystalline metal copper, respectively.

The stress-strain curves for the samples of nano- $\mathrm{Cu}$ with clean and air-contaminated interfaces, as well as of polycrystalline metal copper are shown in Figure 2. The elastic modulus, yield stress, fracture strength and clongation are $84 \mathrm{GPa}, 118 \mathrm{MPa}, 237 \mathrm{MPa}$, and 0.06 , respectively, which are $0.65,1.42,1.82$, and 0.15 times of that of coarse-grained polycopper. The morphology of fracture surfaces of nano-Cu observed by SEM is mainly intergrannular, but with small amount of ductile fracture characteristics. The microhardness of the present sample is 6 times higher than that of poly-Cu. It could be seen from Figure 2 that

Table 1 Positron lifetimes and intensities for nano- $\mathrm{Cu}$ and other nano-materials

\begin{tabular}{||c|cccc|ccc|c|c||}
\hline & & & & & & & & & \\
& $\tau_{1}$ & $\tau_{2}$ & $\tau_{3}$ & $\tau_{4}$ & $I_{1}$ & $I_{2}$ & $I_{3}+I_{4}$ & $I_{1} / I_{2}$ & References \\
& $(\mathrm{ps})$ & $(\mathrm{ps})$ & $(\mathrm{ps})$ & $(\mathrm{ps})$ & $(\%)$ & $(\%)$ & $(\%)$ & & \\
\hline nano-Cu & 175.4 & 345 & 3498 & & 51.7 & 47.7 & 0.6 & 1.08 & \\
& \pm 5 & \pm 7 & \pm 763 & & \pm 3 & \pm 3 & \pm 0.3 & & \\
\hline nano-Fe & 180 & 360 & 1200 & 4000 & & & $10-30$ & $0.5-1.0$ & 10,11 \\
& \pm 15 & \pm 30 & \pm 200 & \pm 500 & & & & & \\
\hline nano-NiP & 152.3 & 350 & 1470 & & 94.4 & 4.5 & 1.1 & 21.0 & 12 \\
& \pm 1.3 & \pm 20 & \pm 96 & \pm 1.3 & \pm 1.2 & \pm 0.1 & & \\
\hline nano- $\mathrm{TiO}_{2}$ & 226 & 385 & 1939 & & 37.9 & 55.9 & 6.2 & 0.67 & 13 \\
& \pm 15 & \pm 16 & \pm 66 & & \pm 8.2 & \pm 8.0 & \pm 0.2 & & \\
\hline \hline
\end{tabular}


the tensile property of the air-contaminated sample is very poor. Its tensile strength is only one fourth of that of nano-Cu with clean interfaces, and its elongation is less than 0.005 .

\section{CONCLUSIONS}

A large disc-shaped specimen of nanocrystalline metal copper with the diameter of 80 $\mathrm{mm}$ and thickness $5 \mathrm{~mm}$ has been successfully synthesized by an inert gas condensation and in-situ warm compacting technique. Its grain size and density are $36 \mathrm{~nm}$ and $94.3 \%$ of standard density, respectively. The measurement of positron lifetime and intensity indicates that the size and amount of monovacancies, vacancy-clusters and microvoids in the large specimen of nano- $\mathrm{Cu}$ are close to that found in the small specimens of other nanostructured materials synthesized by the same technique. The tensile property of nano-Cu shows reduced elastic modulus and ductility, and enhanced yield stress and fracture strength, comparing with that of the coarse-grained polycrystalline metal copper. But the microhardness of nano- $\mathrm{Cu}$ enhances extremely, which is not in proportion to the enhancement of the tensile strength. The degradation of tensile property is observed for the nano-Cu with air-contaminated interfaces.

\section{ACKNOWLEGEMENTS}

This work was suported by the National Natural Science Foundation of China under Grant 59431021 and by the Laboratory for Nonlinear Mechanics of Continuous Media, Institute of Mechanics, Academia Sinica.

\section{REFERENCES}

1. Gleiter,H., Prog. Mater. Sci., 1989, 33, 223.

2. Suryanarayana,S., Mukhopadhyy,D., Pataukov,S.V. and Froes,F.H., J. Mater. Res., 1992, $7,2114$.

3. Siegel,R.W., Mater.Sci. Forum, 1997, 235-238, 851.

4. Qin,X.Y., Wu X.J. and Zhang,L.D., Nanocrystalline Materials, 1995, 5, 101.

5. Nieman,G.W., Weertman J.R. and Siegel,R.W, Scripta Metall. Mater., 1990, $24,145$.

6. Guenther,B., Baalman A. and Weiss,H., Mater. Res. Soc. Symp. Proc., 1990, 195, 611.

7. Nieman,G.W., Weertman J.R. and Siegel,R.W., J.Mater. Res., 1991, 6, 1012.

8. Valiev,R.Z., Mater. Sci. Eng., 1997, A234-236, 59.

9. Rittner,M.N., Weertman,J.R., Eastman,J.A., Yoder,K.B. and Stone,D.S., Mater. Sci. Eng., 1997, A237, 185.

10. Schaefer,H.E., and Wurschum,R., Phys. Lett., 1987, 119A, 370.

11. Schaefer,H.E., Wurschum,R., Birringer.R. and Gleiter,H., Phys. Rev.,1988, B38, 9545.

12. Shi,M.L., Xiong,L.Y., Deng,W., Lu,K. and Patu,S., J. Appl. Phys., 1991, 69, 4451.

13. Xiong,L.Y., Deng,W, Zhu,J., Dupasquier,A., Wu,X.J, and Ji,X.L., Mater. Sci. Forum, $1995,175-178,577$. 